\title{
Longitudinal trajectory of disability in community-dwelling older adults: An observational cohort study in South Korea
}

\author{
Hae Reong Kim ${ }^{1 \dagger}$, Heayon Lee ${ }^{2,3+}$, Yoonje Seong ${ }^{4}$, Eunju Lee ${ }^{2}$, Hee-Won Jung ${ }^{2}$, Yu Rang Park ${ }^{1 *}$ and \\ II-Young Jang ${ }^{2,5}$
}

\begin{abstract}
Background: Disability, which is considered a health-related condition, increases care demands and socioeconomic burdens for both families and communities. To confirm the trend of dynamic longitudinal changes in disability, this study aims to explore how disability is divided by the trajectory method, which deals with time-sequenced data. Additionally, this study examines the differences in demographics, geriatric conditions, and time spent at home among the trajectory groups in community-dwelling older adults. Home time is defined as the period during which the patient was not in a hospital or health care facility during their lifetime.

Methods: Records of 786 community-dwelling older participants were analyzed from the Aging Study of PyeongChang Rural Area, a population-based cohort study that took place over three years. Using 7 domains of activities of daily living and 10 domains of instrumental activities of daily living, participants were grouped into no dependency (0 disabled domain), mild (1 disabled domain), and severe (2 or more disabled domains) disability groups. The longitudinal trajectory group of disability was calculated as a trajectory method. Three distinct trajectory groups were calculated over time: a relatively-stable group $(78.5 \% ; n=617)$, a gradually-aggravated group (16.0\%; $n=126)$, and a rapidly-deteriorated group (5.5\%; $n=43)$.

Results: The average age of 786 participants was 73.3 years (SD: 5.8 ), and the percentage of female was $52.7 \%$. It was found that $78.5 \%$ of patients showed relatively no dependence and $5.5 \%$ of older adults in a rural area showed severe dependence. Through applying the trajectory method, it was shown that the Short Physical Performance Battery (SPPB) score was 10.2 points in the relatively-stable group and 3.1 points in the rapidly-deteriorating group by the 3rd year. Additionally, by the trajectory method, the rate of decrease in home time was 3.33\% in the rapidlydeteriorated group compared to the relatively-stable group.

Conclusions: This study shows the difference in demographics and geriatric conditions (such as SPPB) through the examination of longitudinal trajectory groups of disability in community-dwelling older adults. Significant differences were also found in the amount of home time among the trajectory groups.
\end{abstract}

Keywords: Aged, Disability, Geriatric assessment, Patient-Centered Care, Quality of life, Trajectory

\footnotetext{
*Correspondence: yurangpark@yuhs.ac

${ }^{+}$Hae Reong Kim and Hea yon Lee contributed equally to this work.

${ }^{1}$ Department of Biomedical Systems Informatics, Yonsei University College of Medicine, Seoul, South Korea

Full list of author information is available at the end of the article
}

(c) The Author(s). 2020 Open Access This article is licensed under a Creative Commons Attribution 4.0 International License, which permits use, sharing, adaptation, distribution and reproduction in any medium or format, as long as you give appropriate credit to the original author(s) and the source, provide a link to the Creative Commons licence, and indicate if changes were made. The images or other third party material in this article are included in the article's Creative Commons licence, unless indicated otherwise in a credit line to the material. If material is not included in the article's Creative Commons licence and your intended use is not permitted by statutory regulation or exceeds the permitted use, you will need to obtain permission directly from the copyright holder. To view a copy of this licence, visit http://creativecommons.org/licenses/by/4.0/ The Creative Commons Public Domain Dedication waiver (http://creativecommons.org/publicdomain/zero/1.0/) applies to the data made available in this article, unless otherwise stated in a credit line to the data. 


\section{Background}

The number of countries facing an aging population is increasing worldwide $[1,2]$. The increase in the world's older population implicates an increase in not only the prevalence of chronic diseases, but also the burden of people with functional impairments and geriatric conditions (e.g., frailty and sarcopenia) [3-6]. Particularly, disability, which is regarded as a health-related condition, increases care demands and socioeconomic burdens for both families and communities [7-9].

The onset of disability varies substantially among individuals with similar chronological ages [10-13]. Studies have shown that differences exist among individuals in terms of presence of multimorbidity, frailty, and disability. Evidence also suggests that disability can be prevented or delayed when accompanied by appropriate multifactorial interventions to remove risk factors and improve functioning, making disability one of the most important outcome measures in studies targeting older populations [14].

The conventional method of assessment for disability focuses on the severity of the disability at the initial diagnosis; however, this does not reflect the individuality and time course of the disability. The trajectory method of assessment focuses on the changes in the later years of life [15]. Previous studies have shown different trajectory models based on mood, physical activity, and disability in the later years of life $[8,15-17]$. However, the trajectory and time course of various disabilities are still not well understood. Although some studies show trajectories and subsequent mortality with disability [15], other studies demonstrate that not all older individuals with disability in the community end up being institutionalized in chronic hospitals or other long-term care facilities [1618]. It is unclear whether an older individual identifying with a disability has a high probability of readmission or long-term institutionalization. Furthermore, only a few studies have focused on the dynamic trajectories of disability in community-dwelling older adults [18].

Previously, trajectories of disability were not researched in relation to patient-centered outcomes. Patient-centered outcomes are the result of a healthcare system that prioritizes a patient's needs in conjunction with the healthcare professional's medical expertise. It focuses on health status that is meaningful to patients such as quality of life, functional status, and independent living [19-21]. In recent studies, "home time" has been proposed as a patient-centered measure relevant to the quality of life for older people [22-24]. Home time, meaning the number of days alive and spent at home, comes from the concept of patients' wanting to maximize the number of days they can be at home rather than in hospital or nursing facilities at the end of their life. Home time focuses on priority values and purposes that are important to older patients or their families, and shows its relationship with self-rated health, mobility, self-care difficulties, and limited social activity [22-24].

The objective of this study is to explore the following: (1) how disability is divided by the trajectory method in relation to time-sequenced data in a longitudinal cohort, (2) whether the demographic and geriatric conditions differ among the trajectory groups, and (3) whether home time, a patient-centered outcome, is differentiated by the trajectory groups.

\section{Methods \\ Study design and sample}

Records from the Aging Study of Pyeongchang Rural Area (ASPRA) were analyzed. This population-based, prospective cohort study has been established to analyze aging-related changes and major health outcomes of the older population, as part of an academic-public health collaborative model. The details of this study are described elsewhere [25]. To summarize, older Korean adults in Pyeongchang-gun who met the required criteria were enrolled beginning in November 2014. The inclusion criteria of the ASPRA cohort included: (1) being aged $\geq 65$ years; (2) being registered in the National Healthcare Service; (3) being ambulatory with or without an assistive device; (4) living at home; and (5) being able to provide informed consent. Those who were living in a nursing home, hospitalized, or bed-ridden and receiving nursing-home-level care at the time of enrollment were excluded [25]. The cohort had a participation rate of more than $90 \%$. A baseline study on the ASPRA population showed that demographic characteristics in this population were in accordance with those of nationwide rural-dwelling older adults [25]. The Institutional Review board of Asan Medical Center, Seoul, Korea, approved the protocol for this study (IRB No. 2015-0673).

\section{Assessment of disability}

Trained nurses assessed disability and other geriatric conditions utilizing standardized instruments every year [7]. Disability was assessed according to a 7-item activity of daily living scale (ADL; bathing, continence, dressing, eating, toileting, transferring, and washing face and hands) $[5,26]$, or a 10 -item instrumental activity of daily living scale (IADL; food preparation, household chores, going out short distance, grooming, handling finances, laundry, managing own medications, shopping, transportation, and using a telephone) [5, 27, 28]. Disability was defined as being dependent in more than one domain in ADL and IADL. The severity of disability was conventionally operationalized into three groups: no dependency (disabled domain: 0), mild disability (disabled domain: 1), and severe disability (disabled domain: 2 or more) $[29,30]$. 


\section{Assessment of geriatric conditions}

Participants' baseline demographic factors (e.g., age, sex, education (in years), living alone, and medical aid) were further examined. Physician-diagnosed chronic diseases, including angina, arthritis, asthma, cancer, chronic lung disease, heart failure, diabetes mellitus, heart attack, hypertension, kidney disease, and stroke were identified [5]. Cognitive function was assessed by the Korean version of the Mini Mental State Examination-Dementia Screening [MMSE-DS; ranged from 0 (severe cognitive impairment) to 30 (no problem) [31]. Mood status was examined by the Korean version of the center for Epidemiological Studies Depression scale [CES-D; ranged from 0 (not depressed) to 60 (severely depressed)] [32]. Nutritional status was assessed by a Mini Nutritional AssessmentShort Form [MNA-SF; ranged from 0 (malnutrition) to 14 (well-nourished)] [33]. Physical function was measured using the Short Physical Performance Battery [SPPB; ranged from 0 (worst performance) to 12 (best performance)] that covered chair stand, standing balance, and gait speed [34, 35]. The Korean version of a 5-item FRAIL scale was administered to screen frailty status [36]. Participants were interviewed concerning their history of falls in the past year.

\section{Calculation of home time}

Registered nurses assessed the participants' hospital use, visits to the emergency room, and institutionalization period every three months. Home time was calculated to be 365 days excluding the dates sent from the hospital and healthcare facilities [22, 23].

\section{Statistical analysis}

To identify differences in home time among groups, a one-way analysis of variance (ANOVA) test was utilized for home time, which is a numeric variable. Regarding the categorical variables within the study, the difference among the variables was examined by employing a chisquare test. In order to examine the statistical association between home time and disability group, a Poisson regression model was applied. We estimated the incidence rate ratio (IRR) and 95\% confidence intervals (CI) for home time with a Poisson regression model, adjusted for sex and age in the trajectory group [37]. In the conventional group, the year of measure was additionally adjusted.

Based on the discrepancy of the results, separate trajectories were identified according to the severity of disability using the Proc Traj procedure in SAS 9.4 [38]. The groups were divided according to the following criteria: (a) the lowest value in Bayesian Information Criteria (BIC), (b) the average posterior probability of group assignment $(\geq 0.7)$, and (c) group size such that no less than $5 \%$ of the study sample were assigned to one trajectory group [39]. These analyses were performed with the 3.5.3 version in $\mathrm{R}$. Two-sided $P$ values of $<.05$ were considered statistically significant.

\section{Results}

\section{Total candidates and characteristics}

Of the 1355 participants who received usual care in public health settings, those participants who had a follow-up period of less than three years were excluded. Among individuals, 233 people were excluded because the follow-up period was less than three years. By then, 336 participants dropped out due to either medical reasons $(n=170)$ or follow-up loss $(n=166)$. Among the medical reasons, 35 participants had died, 103 were admitted to nursing homes, and 32 moved out due to health problems. Of the 166 participants with follow-up loss, 53 moved out due to other problems, 89 declined to participate, and 24 had lost contact. Finally, 786 participants who completed routine measurements for three years were analyzed in this study (Fig. 1). For participants with a follow-up period longer than three years, the baseline point was defined as the first measurement after enrollment.

Participants' baseline demographic factors including age, sex, education (in years), living alone (or not), and medical aid (or not) were examined according to total participants based on Fig. 1 (Table 1). Geriatric conditions such as number of comorbidities, MMSE-DS, number of regular medications, FRAIL scale, SPPB score, CES-D score, MNA-SF score, and the number of falls were included. The average age was 73.3 years (SD: 5.8 ), and the percentage of females was $52.7 \%$ of the total. The average education (in years) was 5.2 years (SD: 3.3 ), and $15.8 \%$ of the total were living alone. Among geriatric conditions, the baseline of the SPPB and MMSE-SD score was 8.8 (SD: 2.8) and 25.7 (SD: 3.9), respectively, each at baseline.

\section{Disability trajectories}

Three trajectory groups were defined according to the degree of disability by the number of impaired domains from the 1st to the 3rd years (Fig. 2). The model with three trajectory groups was the best fit for our data based on BIC, considering the proportions of each group (see Table S1 on Additional file 1). The average posterior probability was assigned to each group $(p=0.9,0.82$, and 0.96, respectively) [39].

The "relatively-stable group" (78.5\%; $n=617)$ was characterized by the lowest levels of disability. The "gradually-aggravated group" $(16.0 \% ; n=126)$ was characterized by slightly increasing levels of disability over time. The remaining $5.5 \%$ of the population $(n=43)$ with high baseline disability that was also rapidly aggravating over time were categorized as the "rapidly-deteriorated" group (Fig. 2) [40].

\section{Comparisons of characteristics among trajectory groups}

We looked at factors such as baseline demographic factors and geriatric condition according to the trajectory group likewise in chapter 3.1. (Table 2). 


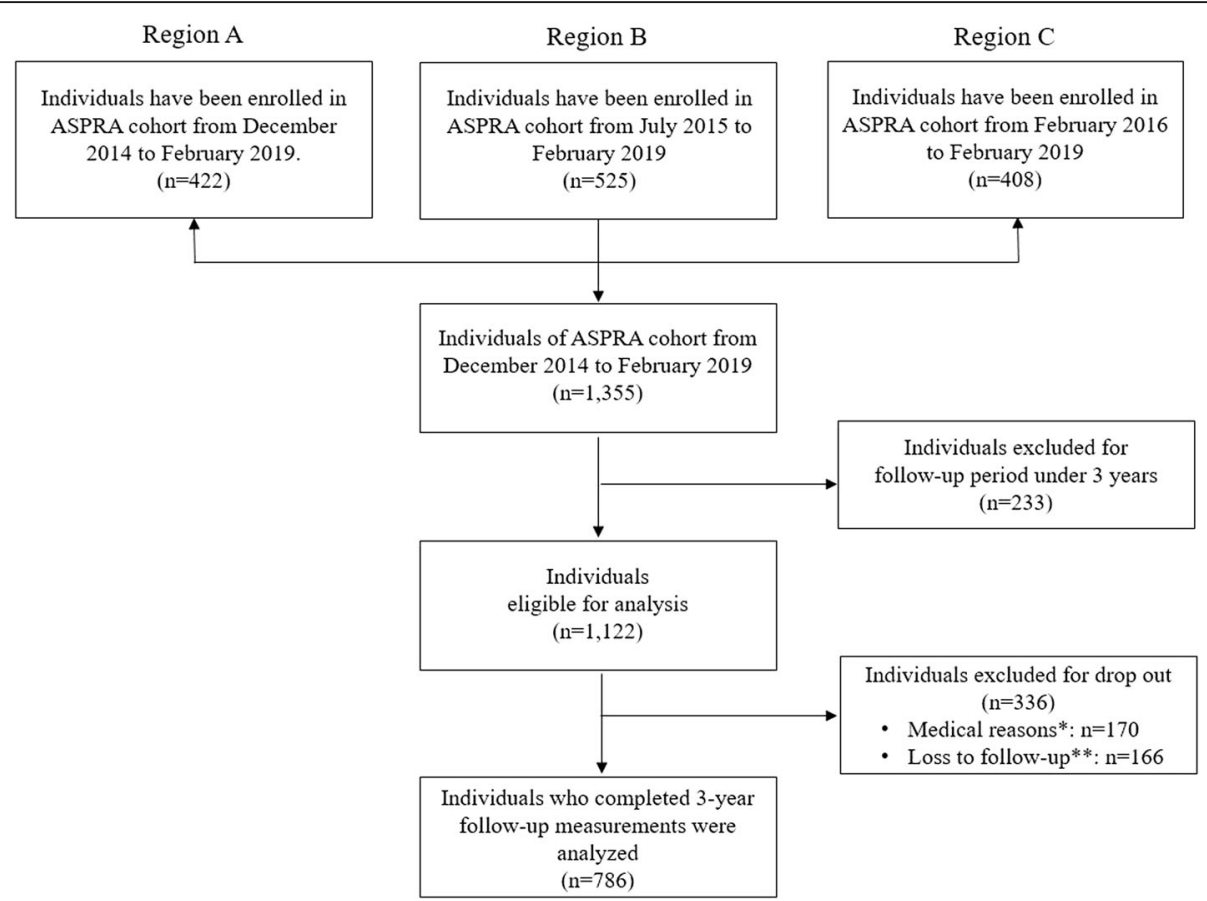

Fig. 1 Participant selection flow. * Among the 170 participants who dropped out for medical reasons, 35 participants (20.6\%) had died, 103 participants (60.6\%) were admitted to nursing homes due to deterioration of health, and 32 participants (18.8\%) had moved or were withdrawn due to health problems. ** Among the 166 participants who dropped out due to follow-up loss, 53 participants (31.9\%) moved due to other problems (except for health), 89 participants (53.6\%) declined to participate, and 24 participants (14.5\%) had lost contact

Geriatric measurements differed significantly in the three groups, except for living alone and the number of falls in the 3rd year. In the 1st year, the relatively-stable group had a mean age of 72.1 years, $45.1 \%$ were female, the mean number of comorbidities was 1.1, the number of medications was 2.2, and the mean number of falls in the previous year was 0.1 . In the rapidly-deteriorated group, mean age at 1st year was 81.1 years (which is almost nine years higher than the relatively-stable group), and $76.7 \%$ of the participants were female. This group had a mean number of 2.0 for comorbidities, 4.4 for those receiving regular medications, and 0.8 for the number of falls in the previous year.

In terms of physical performance, the SPPB score was 9.5 points in the relatively-stable group and 3.3 points in the rapidly-deteriorated group. In the 3rd year, the difference between the relatively-stable group and rapidlydeteriorated group was larger than that of the 1st year, increasing from 6.1 to 7.2 , respectively.

\section{Comparison of home time between the conventional versus trajectory-based group}

Home time decreased by an incremental degree in both the conventional and trajectory-based disability groups (Table 3). Compared to the 1st year, the trend of decreasing home time took place continuously in the 2nd and 3rd year.
In the 1st year, the home time of the severe group was shorter by 8.9 days ( 352.2 days-343.3 days) compared to the no dependency group by conventional grouping. In contrast, the rapidly-deteriorated group had 11.7 days fewer (351.6 days-339.9 days) home time than the relatively-stable group by trajectory-based grouping in the 1st year.

In the 3rd year, the home time of the severe group was shorter by 5.5 days ( 350.3 days -344.8 days) compared to the no dependency group by conventional grouping. By trajectory-based grouping, the rapidly-deteriorated group stayed 8.5 fewer days in their home than in the relativelystable group ( 350.3 days-341.8 days, a $2.43 \%$ decrease).

\section{Incidence rate ratio for home time according to conventional versus trajectory-based grouping of disability}

After recognizing the differences in home time decrements by definitions of disability phenotype (Table 2), regression models were employed to adjust for demographic factors, including age and sex, in these observations. Additionally, the year of measurement was adjusted in the conventional group since the trajectory-based definition already took into account time sequence. In the statistical model with adjusted variables, significant differences of home time between the conventional based and trajectory-based definitions were observed in the univariate analysis (see Table S2 in Additional file 1). 
Table 1 Demographic characteristics and geriatric conditions by total participants

\begin{tabular}{|c|c|c|}
\hline Variable & & Total $(n=786)$ \\
\hline \multirow[t]{10}{*}{ Demographic characteristics } & Age & \\
\hline & mean (SD) & $73.3(5.8)$ \\
\hline & Sex & \\
\hline & female no. (\%) & $414(52.7 \%)$ \\
\hline & Education year & \\
\hline & mean (SD) & $5.2(3.3)$ \\
\hline & Living alone & \\
\hline & no. (\%) & $124(15.8 \%)$ \\
\hline & Medical aid & \\
\hline & no. (\%) & $23(2.9 \%)$ \\
\hline \multicolumn{3}{|l|}{ Severity of disability } \\
\hline \multirow[t]{2}{*}{ Number of ADL domains, mean (SD) } & 1st year & $0.2(0.6)$ \\
\hline & 3 rd year & $0.4(0.8)$ \\
\hline \multirow[t]{2}{*}{ Number of IADL domains, mean (SD) } & 1st year & $0.7(1.5)$ \\
\hline & $3 r d$ year & $1.0(2.1)$ \\
\hline \multicolumn{3}{|l|}{ Geriatric conditions } \\
\hline \multirow[t]{2}{*}{ Number of comorbidities, mean (SD) } & 1st year & $1.3(1.0)$ \\
\hline & 3 rd year & $1.7(1.2)$ \\
\hline \multirow[t]{2}{*}{ SPPB score, mean (SD) } & 1st year & $8.8(2.8)$ \\
\hline & $3 r d$ year & $9.3(2.9)$ \\
\hline \multirow[t]{2}{*}{ MMSE-DS score, mean (SD) } & 1st year & $25.7(3.9)$ \\
\hline & 3rd year & $25.0(4.4)$ \\
\hline \multirow[t]{2}{*}{ CES-D score, mean (SD) } & 1st year & $6.8(8.6)$ \\
\hline & 3rd year & $6.8(9.1)$ \\
\hline \multirow[t]{2}{*}{ MNA-SF score, mean (SD) } & 1st year & $12(1.9)$ \\
\hline & 3rd year & $12.2(1.9)$ \\
\hline \multirow[t]{2}{*}{ Number of regular medications, mean (SD) } & 1st year & $2.6(2.6)$ \\
\hline & 3rd year & $2.6(2.5)$ \\
\hline \multirow[t]{2}{*}{ FRAll scale, mean (SD) } & 1st year & $1.2(1.2)$ \\
\hline & 3 rd year & $1.3(1.2)$ \\
\hline \multirow[t]{2}{*}{ Number of falls (for 12 months), mean (SD) } & 1st year & $0.2(0.8)$ \\
\hline & 3rd year & $0.7(4.8)$ \\
\hline
\end{tabular}

The IRR for home time in the conventional groups and trajectory groups is shown in Fig. 3. Home time in the mild dependent group (IRR $=0.993$; 95\% CI, 0.987-0.999) was shorter than the reference group (no dependency group) by conventional grouping. Similarly, the severe-dependent group had shorter home time (IRR $=0.985$; 95\% CI, 0.9790.992) compared to the no dependency group.

In the trajectory-based group, the home time of the gradually-aggravated group was shorter (IRR $=0.992$; 95\% CI, 0.985-0.999) compared to the relatively-stable group. Similarly, the rapidly-deteriorated group had shorter home time (IRR $=0.978 ; 95 \% \mathrm{CI}, 0.967-0.988$ ) compared to the relatively-stable group.
Incidence rate ratio of subgroup for home time according to trajectory-based grouping of disability

We also conducted subgroup analysis according to age and sex, respectively. In the case of age group, we divided age group criteria into (1) 6574 years, and (2) 75 years or older based on [41]. According to our findings, home time in the female group was lower in the gradually-aggravated group and rapidly-deteriorated group than in the relatively-stable group (IRR, 0.989 and 0.967 ). However, in the male group, there were no significant results for either classification of disability and home time. 


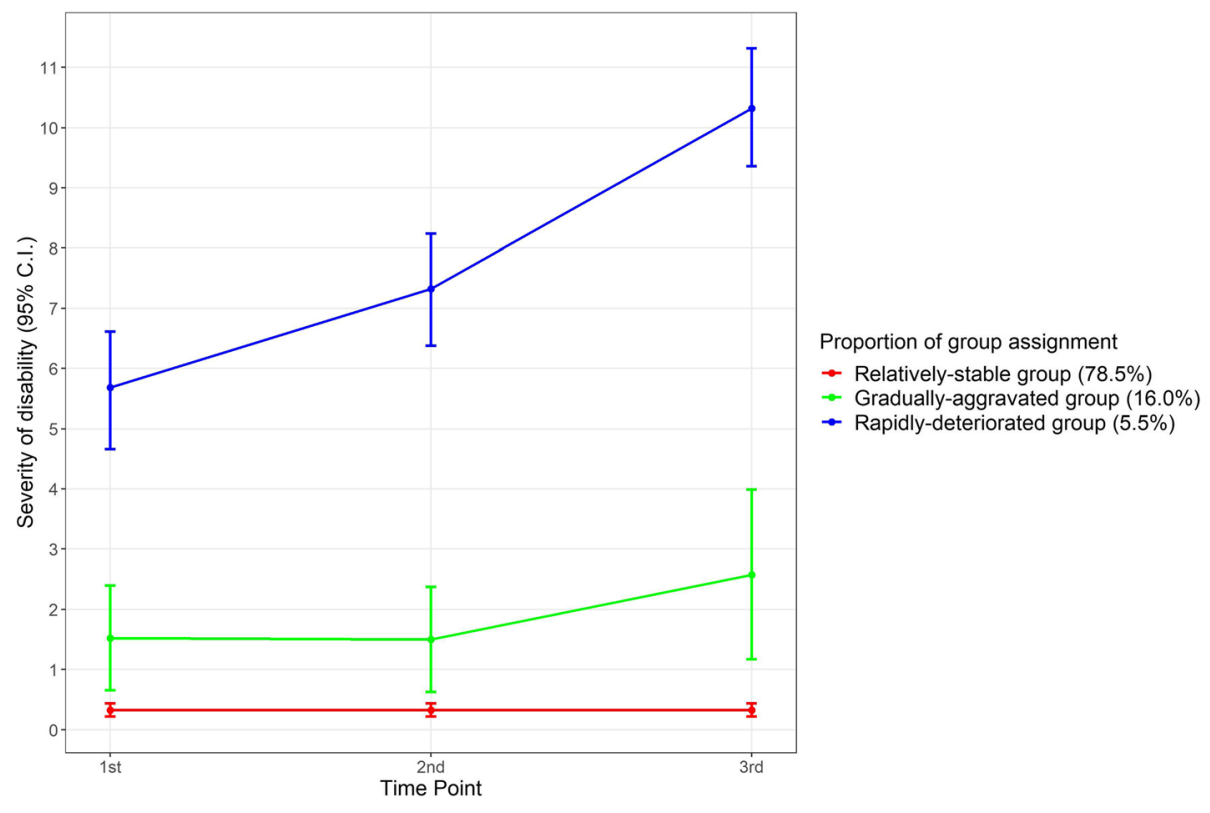

Fig. 2 Trajectory group of disability over time (with 95\% C.I., for 3-years)

In the case of the age group, the IRR for home time in the 65-74 year age group was 0.915 in the rapidlydeteriorated group compared to the relatively-stable group. The portion of the rapidly-deteriorated group was just $1.7 \%$ of the total, however. In the 75 years or older group, the disability classification was proper. But it was not statistically significant with regard to home time (see Table S3, Fig. S1, and S2).

\section{Discussion}

Disability is a major determinant of quality of life in older adults. In the present study, different trajectory groups were categorized according to the severity of disability over time. The conventional method of identifying disability shows only a snapshot of disability status and individual disability components. Therefore, the trajectory groups of disability that we identified demonstrated a more integrated approach toward defining disability.

The major finding of this study is that three trajectory groups with different severities of disability were confirmed in community-dwelling older adults. The three trajectory groups were divided into the following: a relatively-stable group (78.5\%), a gradually-aggravated group (16.0\%), and a rapidly-deteriorated group (5.5\%). Previous studies had shown trajectory grouping using the number of disabilities in patients with underlying diseases such as cancer. In a study with cancer patients, the percentage of the severe trajectory group was $21.2 \%$ prior to receiving cancer treatment [42]. Our study is unique in that we show the percentage of the severe disability group (rapidly-deteriorated group) to be around $5.5 \%$ in relatively healthy older adults living in rural communities. Our data may serve as a basis for future reference in disability studies of the general older populations.

Another finding is that there were differences in the demographic characteristics and geriatric conditions among the different trajectory groups. Most of the variables of the demographic and geriatric conditions were significantly different trajectory groups, except for the number of falls and living alone status. We confirm that the age increased, and the years of education decreased from the relatively-stable to deteriorated group. What stands out most from this study is the change in SPPB. It is well known that SPPB is an important variable for older adults in addition to the FRAIL scale and MMSEDS score [43]. Our results show that in the 3rd year, the SPPB score was 10.2 points (SD: 2.0) in the relativelystable group and 3.1 points (SD: 2.2) in the rapidlydeteriorated (more severe) group. In addition to a statistical difference, the numerical difference shows that there was a difference of more than three times between the relatively-stable group and the rapidly-deteriorated group. From this result, we recommend that a comprehensive geriatric assessment in clinical settings be performed, if available, in order to measure physical performance such as SPPB.

Furthermore, our study contributes to the literature by showing that the trajectory method can maximize the difference in home time compared to the conventional method. We showed that home time decreased more over time, as the disability type was severe at initial diagnosis and the increasing levels of disability were rapid. In the 2nd and 3rd year follow-up, the decrease in home 
Table 2 Demographic characteristics and geriatric conditions by trajectory group

\begin{tabular}{|c|c|c|c|c|}
\hline Variable & Relatively-stable group $(n=617)$ & Gradually-aggravated group $(n=126)$ & Rapidly-deteriorated group $(n=43)$ & $P$ value ${ }^{*}$ \\
\hline \multicolumn{5}{|c|}{ Demographic characteristics } \\
\hline Age & & & & $<.001$ \\
\hline mean (SD) & $72.1(4.9)$ & $76.6(5.9)$ & $81.1(6.6)$ & \\
\hline Sex & & & & $<.001$ \\
\hline female no. (\%) & $278(45.1 \%)$ & $103(81.8 \%)$ & $33(76.7 \%)$ & \\
\hline Education year & & & & $<.001$ \\
\hline mean (SD) & $5.5(3.5)$ & $3.9(2.1)$ & $3.4(1.2)$ & \\
\hline Living alone & & & & 0.382 \\
\hline no. (\%) & $95(15.4 \%)$ & $19(15.1 \%)$ & $10(23.3 \%)$ & \\
\hline Medical aid & & & & 0.001 \\
\hline no. (\%) & $16(2.6 \%)$ & $2(1.6 \%)$ & $5(11.6 \%)$ & \\
\hline \multicolumn{5}{|c|}{ Severity of disability } \\
\hline \multicolumn{5}{|c|}{ Number of ADL domains, mean (SD) } \\
\hline 1st year & $0.1(0.2)$ & $0.3(0.5)$ & $1.3(1.7)$ & $<.001$ \\
\hline 3rd year & $0.2(0.4)$ & $0.6(0.8)$ & $2.5(1.8)$ & $<.001$ \\
\hline \multicolumn{5}{|c|}{ Number of IADL domains, mean (SD) } \\
\hline 1st year & $0.2(0.5)$ & $1.7(1.8)$ & $4.4(2.8)$ & $<.001$ \\
\hline 3rd year & $0.3(0.6)$ & $2.6(1.8)$ & $7.9(1.9)$ & $<.001$ \\
\hline \multicolumn{5}{|c|}{ Geriatric conditions } \\
\hline \multicolumn{5}{|c|}{ Number of comorbidities, mean (SD) } \\
\hline 1st year & $1.1(1.0)$ & $1.6(1.0)$ & $2.0(1.2)$ & $<.001$ \\
\hline 3rd year & $1.6(1.1)$ & $2.1(1.1)$ & $2.4(1.2)$ & $<.001$ \\
\hline \multicolumn{5}{|c|}{ SPPB score, mean (SD) } \\
\hline 1st year & $9.5(2.2)$ & $6.8(2.9)$ & $3.3(2.4)$ & $<.001$ \\
\hline 3rd year & $10.2(2.0)$ & $7.4(3.2)$ & $3.1(2.2)$ & $<.001$ \\
\hline \multicolumn{5}{|c|}{ MMSE-DS score, mean (SD) } \\
\hline 1st year & $26.5(3.4)$ & $23.6(4.0)$ & $20.4(4.7)$ & $<.001$ \\
\hline 3rd year & $26.1(3.3)$ & $21.9(5.1)$ & $18.1(5.0)$ & $<.001$ \\
\hline \multicolumn{5}{|c|}{ CES-D score, mean (SD) } \\
\hline 1st year & $5.4(7.0)$ & $11.8(11)$ & $13.4(12.6)$ & $<.001$ \\
\hline 3rd year & $4.9(6.8)$ & $12.7(12.5)$ & $17.5(12.1)$ & $<.001$ \\
\hline \multicolumn{5}{|c|}{ MNA-SF score, mean (SD) } \\
\hline 1st year & $12.3(1.8)$ & $11.2(2.2)$ & $10.6(2.0)$ & $<.001$ \\
\hline 3rd year & $12.5(1.7)$ & $11.5(2.0)$ & $10.5(2.5)$ & $<.001$ \\
\hline \multicolumn{5}{|c|}{ Number of regular medications, mean (SD) } \\
\hline 1st year & $2.2(2.4)$ & $3.5(2.9)$ & $4.4(3.8)$ & $<.001$ \\
\hline 3rd year & $2.4(2.3)$ & $3.0(2.5)$ & $4.4(3.8)$ & 0.001 \\
\hline \multicolumn{5}{|c|}{ FRAIL scale, mean (SD) } \\
\hline 1st year & $0.9(1.0)$ & $2.1(1.1)$ & $2.5(1.0)$ & $<.001$ \\
\hline 3rd year & $1.0(1.1)$ & $2.2(1.1)$ & $2.7(0.8)$ & $<.001$ \\
\hline \multicolumn{5}{|c|}{ Number of falls (for 12 months), mean (SD) } \\
\hline 1st year & $0.1(0.6)$ & $0.3(0.7)$ & $0.8(2.0)$ & 0.047 \\
\hline 3rd year & $0.3(1.7)$ & $1.6(8.4)$ & $3(12.9)$ & 0.097 \\
\hline
\end{tabular}


Table 3 Home time difference according to conventional versus trajectory-based grouping of disability

\begin{tabular}{|c|c|c|c|c|c|c|c|c|}
\hline \multirow[t]{2}{*}{ Year } & \multicolumn{4}{|c|}{ Conventional Disability Group } & \multicolumn{4}{|c|}{ Trajectory-based Group } \\
\hline & $\begin{array}{l}\text { No dependency } \\
\text { group }(n=518)\end{array}$ & $\begin{array}{l}\text { Mild-dependent } \\
\text { group }(n=154)\end{array}$ & $\begin{array}{l}\text { Severe- } \\
\text { dependent group } \\
(n=114)\end{array}$ & $\begin{array}{l}p \\
\text { value* }\end{array}$ & $\begin{array}{l}\text { Relatively-stable } \\
\text { group }(n=617)\end{array}$ & $\begin{array}{l}\text { Gradually- } \\
\text { aggravated group } \\
(n=126)\end{array}$ & $\begin{array}{l}\text { Rapidly- } \\
\text { deteriorated } \\
\text { group }(n=43)\end{array}$ & $\begin{array}{l}p \\
\text { value* }^{*}\end{array}$ \\
\hline \multicolumn{9}{|c|}{ Home time (days) ${ }^{* *}$, mean (SD) } \\
\hline $\begin{array}{l}1 \mathrm{st} \\
\text { year }\end{array}$ & $352.2(14.3)$ & $348.0(22.3)$ & $343.3(23.1)$ & $<.001$ & $351.6(14.9)$ & $346.0(19.7)$ & $339.9(37.0)$ & 0.003 \\
\hline $\begin{array}{l}2 \text { nd } \\
\text { year }\end{array}$ & $352.0(14.1)$ & $347.7(22.2)$ & $342.9(22.8)$ & $<.001$ & $351.4(14.7)$ & $345.7(19.5)$ & $339.5(36.4)$ & 0.002 \\
\hline $\begin{array}{l}3 r d \\
\text { year }\end{array}$ & $350.3(17.6)$ & $348.2(22.2)$ & $344.8(20.4)$ & 0.025 & $350.3(17.6)$ & $345.5(17.5)$ & $341.8(34.6)$ & 0.009 \\
\hline
\end{tabular}

time was smaller than in the 1st year, but the home time of the trajectory groups were still reduced compared to the conventional groups, and this difference was statistically significant. We found that the trajectory method decreased $3.33 \%$ in the rapidly-deteriorated group compared to the stable group. In the conventional case, the severe-dependent group decreased by $2.53 \%$ compared to the non-dependent group.

The rapidly-deteriorated group had shorter home time (IRR $=0.978 ; 95 \%$ CI, 0.967-0.988) compared to the relatively-stable group by trajectory method. This result was shorter than the severe-dependent group of the conventional method (IRR $=0.985 ; 95 \% \mathrm{CI}, 0.979-0.992$ ).

Considering subgroup, home time in the female group was lower in the gradually-aggravated and rapidlydeteriorated group than in the relatively-stable group (IRR, 0.989 and 0.967), but males and other age groups were not significant in terms of disability classification or home time reduction.

Finally, our results can inform public health professionals developing care models to detect trajectories of disability and build individualized intervention or rehabilitation programs and health policies based on the trajectories, for older, vulnerable populations.

The strengths of this study are that the enrollment rate was $90 \%$ and based on an aging cohort derived from an academic-public health collaborative model. We obtained consistent data based on internationally validated geriatric assessment tools and, therefore, the results reflect real world data. Although our data is based on rural communities where some proportions of individuals have low education and are engaged in agriculture, it is a population-based cohort and the sociodemographic characteristics were similar to those of the representative Korean national data.

This study has several limitations. Among the 1122 eligible participants, 166 people (15\%) were lost to followup. This may be a limitation in constructing the trajectory model, however, this $15 \%$ follow- up loss was over the three years of analysis. Therefore, loss to follow-up occurred around 5\% per year, which is less than the general percentage of population migration. Second, there
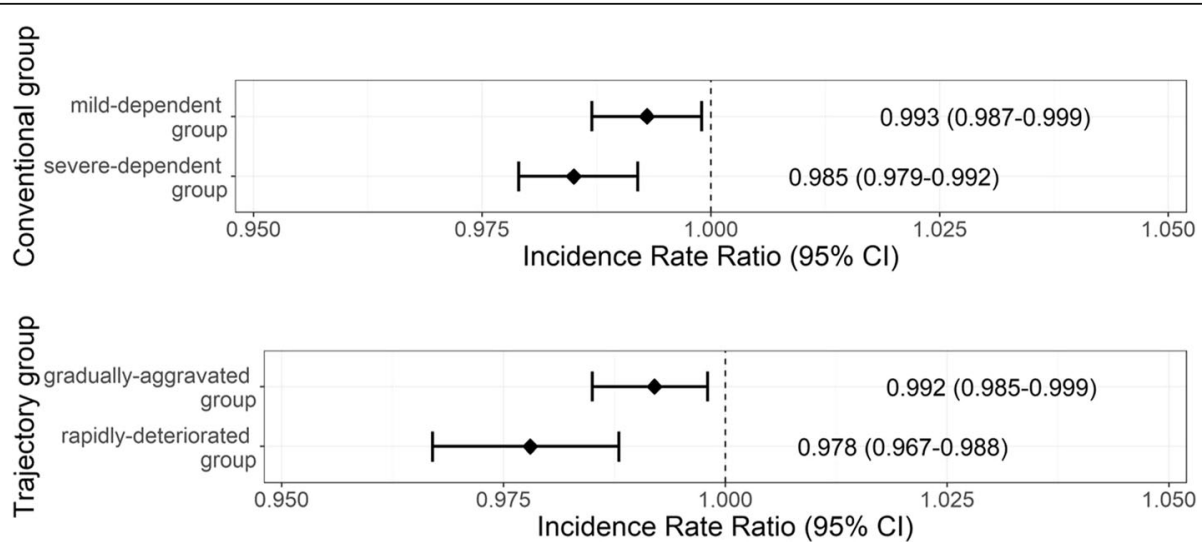

Fig. 3 Forest plot of the incidence rate ratio for conventional versus trajectory group of disability. *The analysis of the trajectory group was adjusted for sex and age. The conventional group was additionally adjusted for the year of measurement. ** The reference value of the conventional group is the 'no dependency group' and the reference value of the trajectory group is the 'relatively-stable group' 
may be a recall bias in home time. The participants may not fully recall their hospital or emergency visits in the previous years. In order to overcome this limitation, we obtained information from Community Health Posts in Pyeonchang run by the National Healthcare Service for information if the participants were not fully aware of their hospital use in the past. Therefore, we attempted to minimize recall bias. Third, there was a relatively short follow-up term. The cohort was a three-year follow-up study and, therefore, there is a need for individuals to be examined over longer periods of time. Lastly, it is difficult to capture the short- and mediumterm changes in disability lasting less than a year by the methods we used. Gill et al. have suggested that mechanisms underlying the different subtypes are likely to differ. While the presence of physical frailty increased the likelihood of developing long-term, recurrent, and unstable disability, it only had a modest effect on developing transient and short-term disability [44].

\section{Conclusions}

A longitudinal trajectory method was used to apply the time trend of disability to community-dwelling older adults. We verify that the demographical and clinical indexes are different according to the trajectory grouping, and the significant effect of the trajectory method on home time was also examined. Our observations provide public health professionals and policy makers with valuable information in order to set priorities for policy making and intervention.

\section{Supplementary information}

Supplementary information accompanies this paper at https://doi.org/10. 1186/s12877-020-01834-y.

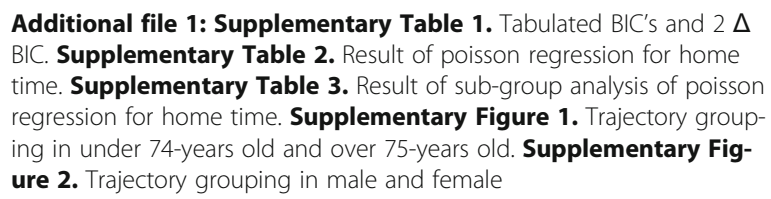

\section{Abbreviations}

ANOVA: Analysis of Variance; BIC: Bayesian information criterion; SPPB: Short Physical Performance Battery; ADL: Activity of Daily Living; IADL: Instrumental Activity of Daily Living; MMSE-DS: Mini Mental State Examination-Dementia Screening; CES-D: Center for Epidemiological Studies Depression scale; MNASF: Mini Nutritional Assessment-Short Form; ASPRA: Aging Study of Pyeongchang Rural Area; IRR: Incidence Rate Ratio

\section{Acknowledgments}

We are indebted to the public health professionals and nurses of PyeongChang County Hospital, Public Health Center, and Community Health Posts for their administrative support and efforts in enrollment and measurements. The abstract of this paper was presented at the American Geriatrics Society (AGS) 2020 Annual Scientific Meeting as an abstract presentation. The poster's abstract was published in "Abstract Supplement" in Journal of the American Geriatrics Society: Currently available at https:// doi.org/10.1111/jgs.16431. The all authors declare that there is no potential conflict of interest regarding the publication of this article.

\section{Authors' contributions}

HRK developed study concept and design, data analysis, data interpretation, drafting, revision of manuscript; HYL developed study concept and design, data analysis, data interpretation, drafting, revision of manuscript; YJS developed study concept and design, data analysis, data interpretation; EJ developed data interpretation, revision of manuscript; HWJ developed data interpretation, revision of manuscript; YRP developed study concept and design, data analysis, data interpretation, drafting, revision of manuscript; IYJ developed study concept and design, data analysis, data interpretation, drafting, revision of manuscript. All the authors contributed to and approved the final manuscript

\section{Funding}

This study was supported by the Foundational Technology Development Program (NRF - 2019M3E5D4064682) the Ministry of Science and ICT, Republic of Korea. This study was also supported by a grant of the Korea Health Technology R\&D Project through the Korea Health Industry Development Institute (KHIDI), funded by the Ministry of Health \& Welfare, Republic of Korea (grant number: H118C2383).

\section{Availability of data and materials}

The datasets used are available from the corresponding author on reasonable request.

\section{Ethics approval and consent to participate}

The protocol approved from the Institutional Review Board of the Asan Medical Center (IRB No. 2015-0673). All participants gave written informed consent to participate before inclusion in the study.

\section{Consent for publication}

Not applicable.

\section{Competing interests}

The authors declare that they have no competing interests.

\section{Author details}

${ }^{1}$ Department of Biomedical Systems Informatics, Yonsei University College of Medicine, Seoul, South Korea. ${ }^{2}$ Division of Geriatrics, Department of Internal Medicine, Asan Medical Center, University of Ulsan College of Medicine, Seoul, South Korea. ${ }^{3}$ Division of Pulmonary, Critical Care and Sleep Medicine, Department of Internal Medicine, Eunpyeong St. Mary's Hospital, College of Medicine, The Catholic University of Korea, Seoul, South Korea. ${ }^{4}$ Yonsei University College of Medicine, Seoul, South Korea. ${ }^{5}$ Pyeongchang Health Center \& Country Hospital, Gangwon-do, South Korea.

Received: 15 March 2020 Accepted: 14 October 2020

Published online: 28 October 2020

\section{References}

1. WHO, Aging UNlo: Global Health and Aging. In:; 2011.

2. Jang IY, Lee HY, Lee E. Geriatrics fact sheet in Korea 2018 from National Statistics. Ann Geriatr Med Res. 2019;23(2):50-3.

3. Fried LP, Ferrucci L, Darer J, Williamson JD, Anderson G. Untangling the concepts of disability, frailty, and comorbidity: implications for improved targeting and care. J Gerontol. 2004;59(3):M255-63.

4. Park B, Ock M, Lee HA, Lee S, Han H, Jo M-W, Park H. Multimorbidity and health-related quality of life in Koreans aged 50 or older using KNHANES 2013-2014. Health Qual Life Outcomes. 2018;16(1):186.

5. Jung HW, Jang IY, Lee YS, Lee CK, Cho El, Kang WY, Chae JH, Lee EJ, Kim $\mathrm{DH}$. Prevalence of frailty and aging-related health conditions in older Koreans in rural communities: a cross-sectional analysis of the aging study of Pyeongchang rural area. J Korean Med Sci. 2016;31(3):345-52.

6. Jang IY, Jung HW, Lee CK, Yu SS, Lee YS, Lee E. Comparisons of predictive values of sarcopenia with different muscle mass indices in Korean rural older adults: a longitudinal analysis of the aging study of PyeongChang rural area. Clin Interv Aging. 2018;13:91-9.

7. James SL, Abate D, Abate KH, Abay SM, Abbafati C, Abbasi N, Abbastabar H, Abd-Allah F, Abdela J, Abdelalim A, et al. Global, regional, and national incidence, prevalence, and years lived with disability for 354 diseases and injuries for 195 countries and territories, 1990-2017: a systematic analysis for the Global Burden of Disease Study 2017. Lancet. 2018;392(10159):1789-858. 
8. Sutin AR, Terracciano A, Milaneschi Y, An Y, Ferrucci L, Zonderman AB. The trajectory of depressive symptoms across the adult life span. JAMA Psychiatry. 2013;70(8):803-11.

9. Kuvalekar K, Kamath R, Ashok L, Shetty B, Mayya S, Chandrasekaran V. Quality of life among persons with physical disability in Udupi Taluk: a cross sectional study. J Fam Med Prim Care. 2015:4(1):69-73.

10. Santoni G, Angleman S, Welmer A-K, Mangialasche F, Marengoni A, Fratiglioni L. Age-related variation in health status after age 60. PLoS One. 2015;10(3):-e0120077.

11. Spillman BC. Changes in elderly disability rates and the implications for health care utilization and cost. Milbank Q. 2004;82(1):157-94.

12. Xue QL, Tian J, Walston JD, Chaves PHM, Newman AB, Bandeen-Roche K. Discrepancy in Frailty Identification: Move beyond Predictive Validity. The journals of gerontology Series A, Biological sciences and medical sciences 2019.

13. Kim KJ, Shin J, Choi J, Won CW. Discrepancies in the prevalence of known frailty scales: Korean frailty and aging cohort study. Ann Geriatr Med Res. 2018;22(3):137-44

14. Jang IY, Jung HW, Park H, Lee CK, Yu SS, Lee YS, Lee E, Glynn RJ, Kim DH. A multicomponent frailty intervention for socioeconomically vulnerable older adults: a designed-delay study. Clin Interv Aging. 2018;13:1799-814.

15. Gill TM, Gahbauer EA, Han L, Allore HG. Trajectories of disability in the last year of life. N Engl J Med. 2010;362(13):1173-80.

16. Laddu D, Parimi N, Cauley JA, Cawthon PM, Ensrud KE, Orwoll E, Stefanick M, Langsetmo L. The Association between Trajectories of Physical Activity and All-cause and Cause-specific Mortality. The journals of gerontology Series A, Biological sciences and medical sciences 2018

17. Gill TM, Gahbauer EA, Han L, Allore HG. The role of intervening hospital admissions on trajectories of disability in the last year of life: prospective cohort study of older people. BMJ. 2015;350:h2361.

18. Gill TM, Gahbauer EA, Leo-Summers L, Murphy TE, Han L. Days spent at home in the last six months of life among community-living older persons. Am J Med. 2019;132(2):234-9.

19. Herr M, Arvieu J-J, Aegerter P, Robine J-M, Ankri J. Unmet health care needs of older people: prevalence and predictors in a French cross-sectional survey. Eur J Pub Health. 2014;24(5):808-13.

20. Concannon TW. Can patient centered outcomes research improve healthcare? BMJ. 2015;351:h3859.

21. Stewart M, Brown JB, Donner A, McWhinney IR, Oates J, Weston WW, Jordan J. The impact of patient-centered care on outcomes. J Fam Pract. 2000;49(9):796-804.

22. Lee H, Shi SM, Kim DH. Home time as a patient-centered outcome in administrative claims data. J Am Geriatr Soc. 2019;67(2):347-51.

23. Groff AC, Colla CH, Lee TH. Days spent at home - a patient-centered goal and outcome. N Engl J Med. 2016;375(17):1610-2.

24. Greene SJ, O'Brien EC, Mentz RJ, Luo N, Hardy NC, Laskey WK, Heidenreich PA, Chang C-L, Turner SJ, Yancy CW, et al. Home-time after discharge among patients hospitalized with heart failure. J Am Coll Cardiol. 2018; 71(23):2643-52.

25. Jung H-W, Jang I-Y, Lee YS, Lee CK, Cho E-I, Kang WY, Chae JH, Lee EJ, Kim $\mathrm{DH}$. Prevalence of frailty and aging-related health conditions in older Koreans in rural communities: a cross-sectional analysis of the aging study of Pyeongchang rural area. J Korean Med Sci. 2016;31(3):345-52.

26. Azad A, Mohammadinezhad T, Taghizadeh G, Lajevardi L. Clinical assessment of activities of daily living in acute stroke: validation of the Persian version of Katz index. Med J Islam Repub Iran. 2017;31:30.

27. Lawton MP, Brody EM. Assessment of older people: self-maintaining and instrumental activities of daily living. Gerontologist. 1969;9(3):179-86.

28. Jung HW, Kim JW, Han JW, Kim K, Kim JH, Kim Kl, Kim CH, Kim KW. Multidimensional geriatric prognostic index, based on a geriatric assessment, for long-term survival in older adults in Korea. PLoS One. 2016; 11(1):e0147032.

29. Kempen GIJM, Myers AM, Powell LE. Hierarchical structure in ADL and IADL: analytical assumptions and applications for clinicians and researchers. J Clin Epidemiol. 1995;48(11):1299-305.

30. Spector WD, Fleishman JA. Combining activities of daily living with instrumental activities of daily living to measure functional disability. J Gerontol Ser B Psychol Sci Soc Sci. 1998;53(1):S46-57.

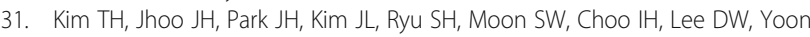
$J C$, Do YJ, et al. Korean version of mini mental status examination for dementia screening and its' short form. Psychiatry Investig. 2010;7(2):102-8.

32. Park JH, Kim KW. A review of the epidemiology of depression in Korea. Korean Med Assoc. 2011;54(4):362-9.
33. Rubenstein LZ, Harker JO, Salvà A, Guigoz Y, Vellas B. Screening for undernutrition in geriatric practice developing the short-form mini-nutritional assessment (MNA-SF). J Gerontol Ser A Biol Med Sci. 2001;56(6):M366-72.

34. Jung HW, Roh H, Cho Y, Jeong J, Shin YS, Lim JY, Guralnik JM, Park J. Validation of a multi-sensor-based kiosk for short physical performance battery. J Am Geriatr Soc. 2019.

35. Jung HW, Roh HC, Kim SW, Kim S, Kim M, Won CW. Cross-comparisons of gait speeds by automatic sensors and a stopwatch to provide converting formula between measuring modalities. Ann Geriatr Med Res. 2019;23(2):71-6.

36. Jung HW, Yoo HJ, Park SY, Kim SW, Choi JY, Yoon SJ, Kim CH, Kim Kl. The Korean version of the FRAIL scale: clinical feasibility and validity of assessing the frailty status of Korean elderly. Korean J Internal Med. 2016;31(3):594-600.

37. Zaitsu M, Kurita Y, Iwahana M, Akiyama H, Watanabe F, Higashikawa A, Kaneko R, Konishi R, Itoh M, Kobayashi Y. Hypnotics use and falls in hospital inpatients stratified by age. Global J Health Sci. 2017;9:148-56.

38. Allen NB, Siddique J, Wilkins JT, Shay C, Lewis CE, Goff DC, Jacobs DR Jr, Liu $\mathrm{K}$, Lloyd-Jones D. Blood pressure trajectories in early adulthood and subclinical atherosclerosis in middle age. Jama. 2014;311(5):490-7.

39. Xiang X. Seven-year trajectories of depressive symptoms and their predictors among older Americans. J Aging Health. 2019:898264319852835.

40. Kim JH, Lee SG, Kim TH, Choi Y, Lee Y, Park EC. Influence of social engagement on mortality in Korea: analysis of the Korean longitudinal study of aging (2006-2012). J Korean Med Sci. 2016;31(7):1020-6.

41. Park CHK, Lee JW, Lee SY, Shim S-H, Kim SG, Lee J, Kim M-H, Paik J-W, Cho S-J, Moon J-J, et al. Characteristics of the "young-old" and "old-old" community-dwelling suicidal Ideators: a longitudinal 6-month follow-up study. Compr Psychiatry. 2019;89:67-77.

42. Presley CJ, Han L, Leo-Summers L, Hurria A, Gross CP, Davidoff AJ, Allore $H G$, Gill TM. Functional trajectories before and after a new cancer diagnosis among community-dwelling older adults. J Geriatric Oncol. 2019;10(1):60-7.

43. Guralnik JM, Simonsick EM, Ferrucci L, Glynn RJ, Berkman LF, Blazer DG, Scherr PA, Wallace RB. A short physical performance battery assessing lower extremity function: association with self-reported disability and prediction of mortality and nursing home admission. J Gerontol. 1994;49(2):M85-94.

44. Gill TM, Guo Z, Allore HG. Subtypes of disability in older persons over the course of nearly 8 years. J Am Geriatr Soc. 2008;56(3):436-43.

\section{Publisher's Note}

Springer Nature remains neutral with regard to jurisdictional claims in published maps and institutional affiliations.

Ready to submit your research? Choose BMC and benefit from:

- fast, convenient online submission

- thorough peer review by experienced researchers in your field

- rapid publication on acceptance

- support for research data, including large and complex data types

- gold Open Access which fosters wider collaboration and increased citations

- maximum visibility for your research: over $100 \mathrm{M}$ website views per year

At $\mathrm{BMC}$, research is always in progress.

Learn more biomedcentral.com/submission 